\title{
PRODUCTION OF METHANE FROM CARBON MONOXIDE AND CARBON DIOXIDE IN A PLASMA-CATALYTIC COMBINED REACTOR SYSTEM
}

\author{
Y.S. MOK, E. JWA \& H.W. LEE \\ Department of Chemical and Biological Engineering, Jeju National University, Korea.
}

\begin{abstract}
Plasma-catalytic hydrogenation of $\mathrm{CO}$ and $\mathrm{CO}_{2}$ for producing methane was investigated with a catalyst-packed dielectric barrier discharge reactor. The characteristics of methane production from $\mathrm{CO} / \mathrm{H}_{2}$ or $\mathrm{CO}_{2} / \mathrm{H}_{2}$ gas mixture were examined with bare alumina, $\mathrm{TiO}_{2}$ /alumina, $\mathrm{Ni} /$ alumina, and $\mathrm{Ni}-\mathrm{TiO}_{2} /$ alumina under plasma and non-plasma conditions. The results obtained with bare alumina and $\mathrm{TiO}_{2} /$ alumina suggest that either plasmainduced gas-phase reactions or photocatalytic reactions hardly contribute to the conversion of $\mathrm{CO}$ and $\mathrm{CO}_{2}$. The nonthermal plasma was found to have a promotive effect on the conversion of $\mathrm{CO}$ and $\mathrm{CO}_{2}$ only when nickel-loaded catalysts such as $\mathrm{Ni} /$ alumina and $\mathrm{Ni}-\mathrm{TiO}_{2}$ /alumina were used, implying that the nonthermal plasma serves to promote the dissociation of carbon-oxygen bonds of $\mathrm{CO}$ and $\mathrm{CO}_{2}$ adsorbed on the active sites of the catalysts, known as the slowest step of the reaction.

Keywords: catalytic hydrogenation, $\mathrm{CO}, \mathrm{CO}_{2}$, methane, nonthermal plasma.
\end{abstract}

\section{INTRODUCTION}

Methane is the primary component of natural gas that is not only an important energy source but also a valuable feedstock for the chemical industry. The catalytic conversion of carbon oxides ( $\mathrm{CO}$ and $\mathrm{CO}_{2}$ ) into methane is increasingly attracting attention, because it can provide measures for utilizing coal-derived synthesis gas effectively and a possibility for recycling $\mathrm{CO}_{2}$ back into fuel. This is also actuated in part by the relative abundance of coal and the need to develop a clean coal technology. Increasing consumption - and the resultant increasing price - of natural gas are a concern. There are several advantages associated with producing synthetic natural gas (SNG) from coal, as it could be a major drive for energy security and diversify energy options [1]. Since coal is relatively abundant and evenly distributed globally, as compared to petroleum and natural gas, SNG production could also help stabilize the global energy market.

The hydrogenation of carbon oxides to produce methane is called methanation, which is one of essential steps for SNG production, together with coal gasification step. The solid catalysts commonly used for methane production are based on transition metals supported on metal oxides, such as alumina, titanium dioxide, and zeolite [2-5]. Even though the catalysts consisting of a noble metal, such as ruthenium, rhodium or platinum $[2,6]$, nickel-based catalysts have been the most widely studied because nickel is cheap and easily available and shows high activity [5,7-9]. One of the disadvantages of the nickel-based catalysts may be that relatively high temperatures are needed to maintain the catalytic activity for methane production.

The catalysts can chemically be modified with support materials and additives so that they have an enhanced low-temperature activity. Alternatively, the catalytic activity can be improved by a physical means, such as nonthermal plasma and ultraviolet irradiation. In the literature, many studies dealing with combined use of nonthermal plasma and solid catalysis have been reported, which include oxidation of volatile organic compounds, degradation of halogenated carbons, steam reforming of hydrocarbons, $\mathrm{CO}_{2}$ reforming of methane, etc. [10-14]. In a similar manner, nonthermal plasma can also promote the catalytic hydrogenation of $\mathrm{CO}$ and $\mathrm{CO}_{2}$ into methane, as demonstrated in a previous study, where it was shown that the plasma significantly increased the catalytic activity, 
especially at lower temperatures and pressures that the catalyst was not so active $[15,16]$. In a traditional thermal catalysis, catalysts are activated by thermal energy to go over an activation barrier. By comparison, in plasma-catalysis, catalyst is directly in contact with plasma, and reactive species, such as energetic electrons, free radicals, excited atoms, and molecules, generated by the plasma can activate reactant molecules either in the gas phase or on the catalyst surface, possibly leading to the triggering of catalytic reactions at low temperatures. The bond strengths for gaseous $\mathrm{CO}$ and $\mathrm{CO}_{2}$ are $11 \mathrm{eV}$ and $8 \mathrm{eV}$, respectively, but they get weak when adsorbed on the catalyst surface. As a result, the energetic electrons produced by the plasma can readily break the carbon-oxygen bond of the adsorbed carbon oxides. Once the carbon-oxygen bond is broken somehow, the adsorbed carbon is easily hydrogenated to produce methane.

In this work, the production of methane from $\mathrm{CO}$ and $\mathrm{CO}_{2}$ was performed in a dielectric barrier discharge (DBD), nonthermal plasma reactor packed with catalyst pellets at atmospheric pressure. The effect of the plasma discharge on the conversion of $\mathrm{CO}$ and $\mathrm{CO}_{2}$ was comparatively examined with four catalysts, that is, bare alumina, $\mathrm{TiO}_{2}$ /alumina, $\mathrm{Ni}$ /alumina, and $\mathrm{Ni}-\mathrm{TiO}_{2}$ /alumina to understand the role of the plasma and find out how effective the plasma-catalysis is in the production of methane. The nickel-based catalysts used can catalyze the methanation of both $\mathrm{CO}$ and. $\mathrm{CO}_{2}$. The experiments were carried out by varying reactor temperature under plasma and non-plasma conditions at constant $\mathrm{CO} / \mathrm{H}_{2}$ and $\mathrm{CO}_{2} / \mathrm{H}_{2}$ ratios in the feed gas.

\section{THEORETICAL BACKGROUND}

\subsection{Reaction equilibrium}

The catalytic hydrogenation of $\mathrm{CO}$ and $\mathrm{CO}_{2}$ proceeds fast over various transition metal catalysts involving the following overall reactions [4]:

$$
\begin{gathered}
\mathrm{CO}+3 \mathrm{H}_{2} \rightarrow \mathrm{CH}_{4}+\mathrm{H}_{2} \mathrm{O} \\
\mathrm{CO}_{2}+4 \mathrm{H}_{2} \rightarrow \mathrm{CH}_{4}+2 \mathrm{H}_{2} \mathrm{O}
\end{gathered}
$$

Reaction (1) represents the reverse steam reforming reaction, which also proceeds effectively over transition metal catalysts. Thermodynamic values of relevant reactions are tabulated in Table 1 [17].

Table 1: Standard heats and Gibbs free energies at 298K.

\begin{tabular}{lcc}
\hline Reaction & $\Delta H_{298}^{\circ}\left(\mathrm{cal} \mathrm{mol}^{-1}\right)$ & $\Delta G_{298}^{\mathrm{o}}\left(\mathrm{cal} \mathrm{mol}^{-1}\right)$ \\
\hline $\mathrm{C}(\mathrm{s})+\frac{1}{2} \mathrm{O}_{2}(\mathrm{~g}) \rightarrow \mathrm{CO}(\mathrm{g})$ & $-26,416$ & $-32,781$ \\
$\mathrm{C}(\mathrm{s})+\mathrm{O}_{2}(\mathrm{~g}) \rightarrow \mathrm{CO}_{2}(\mathrm{~g})$ & $-94,051$ & $-94,258$ \\
$\mathrm{C}(\mathrm{s})+2 \mathrm{H}_{2}(\mathrm{~g}) \rightarrow \mathrm{CH}_{4}(\mathrm{~g})$ & $-17,889$ & $-12,140$ \\
$\mathrm{H}_{2}(\mathrm{~g})+\frac{1}{2} \mathrm{O}_{2}(\mathrm{~g}) \rightarrow \mathrm{H}_{2} \mathrm{O}(\mathrm{g})$ & $-57,798$ & $-54,635$ \\
$\mathrm{CO}+3 \mathrm{H}_{2} \rightarrow \mathrm{CH}_{4}+\mathrm{H}_{2} \mathrm{O}$ & $-49,271$ & $-33,994$ \\
$\mathrm{CO}_{2}+4 \mathrm{H}_{2} \rightarrow \mathrm{CH}_{4}+2 \mathrm{H}_{2} \mathrm{O}$ & $-39,434$ & $-27,152$ \\
\hline
\end{tabular}


Reactions (1) and (2) are strongly exothermic, which indicates that these reactions favor low reaction temperatures from the chemical equilibrium point of view. It should be noted, however, that reactions (1) and (2) kinetically become favorable as the temperature rises because of the activation energy barrier.

The equilibrium constant $(K)$ is a function of temperature and related to the Gibbs free energy $\left(\Delta G^{\circ}\right)$ and the enthalpy change of a reaction $\left(\Delta H^{\circ}\right)$ as follows [17]:

$$
\begin{aligned}
& \ln K=-\frac{\Delta G^{\mathrm{o}}}{R T} \\
& \frac{d \ln K}{d T}=\frac{\Delta H^{\mathrm{o}}}{R T^{2}}
\end{aligned}
$$

where $T$ is absolute temperature and $R$ is the gas constant. Over a small temperature range, the term $\Delta H^{\circ}$ can be treated as a constant, and eqn (4) is easily integrated to give

$$
\ln \frac{K}{K_{298}}=-\frac{\Delta H_{298}^{\mathrm{o}}}{R}\left(\frac{1}{T}-\frac{1}{298}\right) .
$$

where the subscript '298' denotes a temperature of $298 \mathrm{~K}$ and $K_{298}$ can be calculated using eqn (3) and the data in Table 1. Once $K_{298}$ is known, eqn (5) allows us to determine the equilibrium constants for reactions (1) and (2) at any temperature of interest. To predict the effect of change in temperature on equilibrium conversions of $\mathrm{CO}$ and $\mathrm{CO}_{2}$, following equilibrium expressions should be considered:

$$
\begin{gathered}
K_{\mathrm{CO}}=\frac{P_{\mathrm{CH}_{4}} P_{\mathrm{H}_{2} \mathrm{O}}}{P_{\mathrm{CO}} P_{\mathrm{H}_{2}}^{3}} \text {, for CO methanation. } \\
K_{\mathrm{CO}_{2}}=\frac{P_{\mathrm{CH}_{4}} P_{\mathrm{H}_{2} \mathrm{O}}^{2}}{P_{\mathrm{CO}_{2}} P_{\mathrm{H}_{2}}^{4}} \text {, for } \mathrm{CO} 2 \text { methanation. }
\end{gathered}
$$

Here, $P$ stands for partial pressure. For the present work, the total pressure was maintained at 1.0 atm, and thus eqns (6) and (7) can also be written with respect to mole fractions.

\subsection{Catalytic methanation mechanisms}

The production of methane from $\mathrm{CO}$ and $\mathrm{CO}_{2}$ consists of several elementary reaction steps that sum up to overall reactions (1) and (2). Previous studies that have dealt with mechanistic aspects of catalytic $\mathrm{CO}$ conversion can be classified into two categories: carbide mechanism and $\mathrm{CO}$ insertion mechanism $[8,18,19]$.

The carbide mechanism explains the formation of methane with dissociative adsorption of both carbon monoxide and hydrogen followed by stepwise hydrogenation of adsorbed carbon to produce methane [8]:

$$
\begin{aligned}
& \mathrm{CO}+*=\mathrm{CO} * \\
& \mathrm{H}_{2}+2 *=2 \mathrm{H} *
\end{aligned}
$$




$$
\begin{gathered}
\mathrm{CO} *+*=\mathrm{C} *+\mathrm{O} * \\
\mathrm{C} *+\mathrm{H} *=\mathrm{CH} *+* \\
\mathrm{CH} *+\mathrm{H} *=\mathrm{CH}_{2} *+* \\
\mathrm{CH}_{2} *+\mathrm{H} *=\mathrm{CH}_{3} *+* \\
\mathrm{CH}_{3} *+\mathrm{H} *=\mathrm{CH}_{4}+2 *
\end{gathered}
$$

The symbol (*) used in reactions (8)-(14) signifies a vacant site and chemical formulae with this symbol refers to an adsorbed state. Meanwhile, the $\mathrm{CO}$ insertion mechanism assumes molecular adsorption of $\mathrm{CO}$ and hydrogenation of adsorbed $\mathrm{CO}$ to give an oxygenated intermediate, which further reacts with adsorbed hydrogen to form methane [18]. The important elementary steps accounting for the $\mathrm{CO}$ insertion mechanism are summarized below.

$$
\begin{gathered}
\mathrm{CO} *+\mathrm{H} *=\mathrm{HCO} *+* \\
\mathrm{HCO} *+\mathrm{H} *=\mathrm{HCHO} *+* \\
\mathrm{HCHO} *+\mathrm{H} *=\mathrm{CH} *+\mathrm{H}_{2} \mathrm{O} *
\end{gathered}
$$

As in reactions (12)-(14), $\mathrm{CH} *$ is successively hydrogenated to produce methane:

$$
\mathrm{CH}^{*} \stackrel{+\mathrm{H}^{*}}{\longrightarrow} \mathrm{CH}_{2}{ }^{*} \stackrel{+\mathrm{H}^{*}}{\longrightarrow} \mathrm{CH}_{3}{ }^{*} \stackrel{+\mathrm{H}^{*}}{\longrightarrow} \mathrm{CH}_{4}{ }^{*} \text {. }
$$

Sehested et al. [5] proposed a kinetic model with the dissociation of $\mathrm{CO} *$ as the slowest step, that is, the rate-determining step. According to Bengaard et al. [20], the dissociation of CO* shows the highest barrier among the elementary steps, suggesting that this reaction is the rate-determining step. On the other hand, Alstrup [8] obtained good agreements between experimental data and kinetic model by postulating the hydrogenation reaction between $\mathrm{CH} *$ and $\mathrm{H} *$ as the rate-determining step. Thomson et al. [18] suggested that the rate-determining step is either the hydrogenation of $\mathrm{CH} *$ for the carbide mechanism or the hydrogenation of $\mathrm{HCO} *$ for the $\mathrm{CO}$ insertion mechanism. Whatever elementary reaction acts as the rate-determining step, nonthermal plasma may enhance the rate of methane production, because the adsorption characteristics of the molecules excited by the plasma should be different from those of ground-state molecules and the plasma can help dissociate adsorbed molecules through various processes like direct electron impact. Note that the bond strength of an adsorbed molecule is much weaker than in the gaseous state, which implies that the plasma is more easily capable of cleaving the bond of adsorbed molecule.

As understood in reaction (2), the hydrogenation of $\mathrm{CO}_{2}$ to methane requires more hydrogen than that of CO. Regarding the catalytic methanation mechanism, previous studies reported that $\mathrm{CO}_{2}$ adsorbs dissociatively on the catalyst surface and $\mathrm{CO} *$ is converted into methane via the same reaction steps as in the $\mathrm{CO}$ methanation. The elementary reaction steps for $\mathrm{CO}_{2}$ methanation are as follows [21]:

$$
\begin{gathered}
\mathrm{CO}_{2} *+*=\mathrm{CO} *+\mathrm{O} * \\
\mathrm{CO} *+*=\mathrm{C} *+\mathrm{O} * \\
2 \mathrm{CO} *=\mathrm{C} *+*+\mathrm{CO}_{2}
\end{gathered}
$$

Just like the case of $\mathrm{CO}$ methanation, the hydrogenation of the adsorbed carbon proceeds stepwise by reactions (11)-(14). 


\section{EXPERIMENTAL ANALYSIS}

The experimental setup for the production of methane from $\mathrm{CO}$ and $\mathrm{H}_{2}$ is shown in Fig. 1. The system consisted of four major parts: feed gas preparation, reactor, power supply, and analyzer. The DBD reactor packed with catalyst pellets was made of a quartz tube and a concentric stainless-steel rod acting as the discharging electrode. Details of the reactor, including its configuration and dimensions, are described in our previous article [16]. The effective length of the plasma reactor was 110 $\mathrm{mm}$, and the amount of catalyst pellets packed was $17 \mathrm{~cm}^{3}$ or $13.6 \mathrm{~g}$. The reactor was powered by an alternating current $(\mathrm{AC})$ high voltage (operating frequency: $1 \mathrm{kHz}$ ). The voltage applied to the reactor was changed in the range of $0-11 \mathrm{kV}$. The catalysts used in this work were prepared with alumina ball (Sigma-Aldrich Co.) as the catalyst support, titanium dioxide (anatase $\mathrm{TiO}_{2}$, Sigma-Aldrich Co.), and nickel nitrate $\left(\mathrm{Ni}\left(\mathrm{NO}_{3}\right)_{2} \cdot 6 \mathrm{H}_{2} \mathrm{O}\right.$, Acros Organics). As well known, the anatase form of titanium dioxide acts as a photocatalyst under ultraviolet light. The preparation method of the catalysts has been described in detail in Jwa et al. [16]. The Brunauer-Emmett-Teller (BET) specific surface areas of the catalysts were measured with a surface area analyzer (Model ASAP2010, Micromeritics). The information on the catalysts is summarized in Table 2.

The feed gas was prepared by mixing pure hydrogen and carbon monoxide or by mixing pure hydrogen and carbon dioxide via a set of mass flow controllers (MKS Instruments, Inc.). For the methanation of $\mathrm{CO}$, the molar ratio of $\mathrm{H}_{2}$ to $\mathrm{CO}$ in the feed gas was adjusted to 3 by the stoichiometry. The methanation of $\mathrm{CO}_{2}$ was separately conducted with a $\mathrm{H}_{2} / \mathrm{CO}_{2}$ molar ratio of 4 . The flow rate of the feed gas was $12,000 \mathrm{~cm}^{3} \mathrm{~h}^{-1}$ for $\mathrm{CO}$ methanation, and $15,000 \mathrm{~cm}^{3} \mathrm{~h}^{-1}$ for $\mathrm{CO}_{2}$ methanation. Methanation experiments were performed over the temperature range up to $320^{\circ} \mathrm{C}$ with an interval of $20^{\circ} \mathrm{C}$. The feed gas entered the mixing chamber where it was preheated to desired temperatures

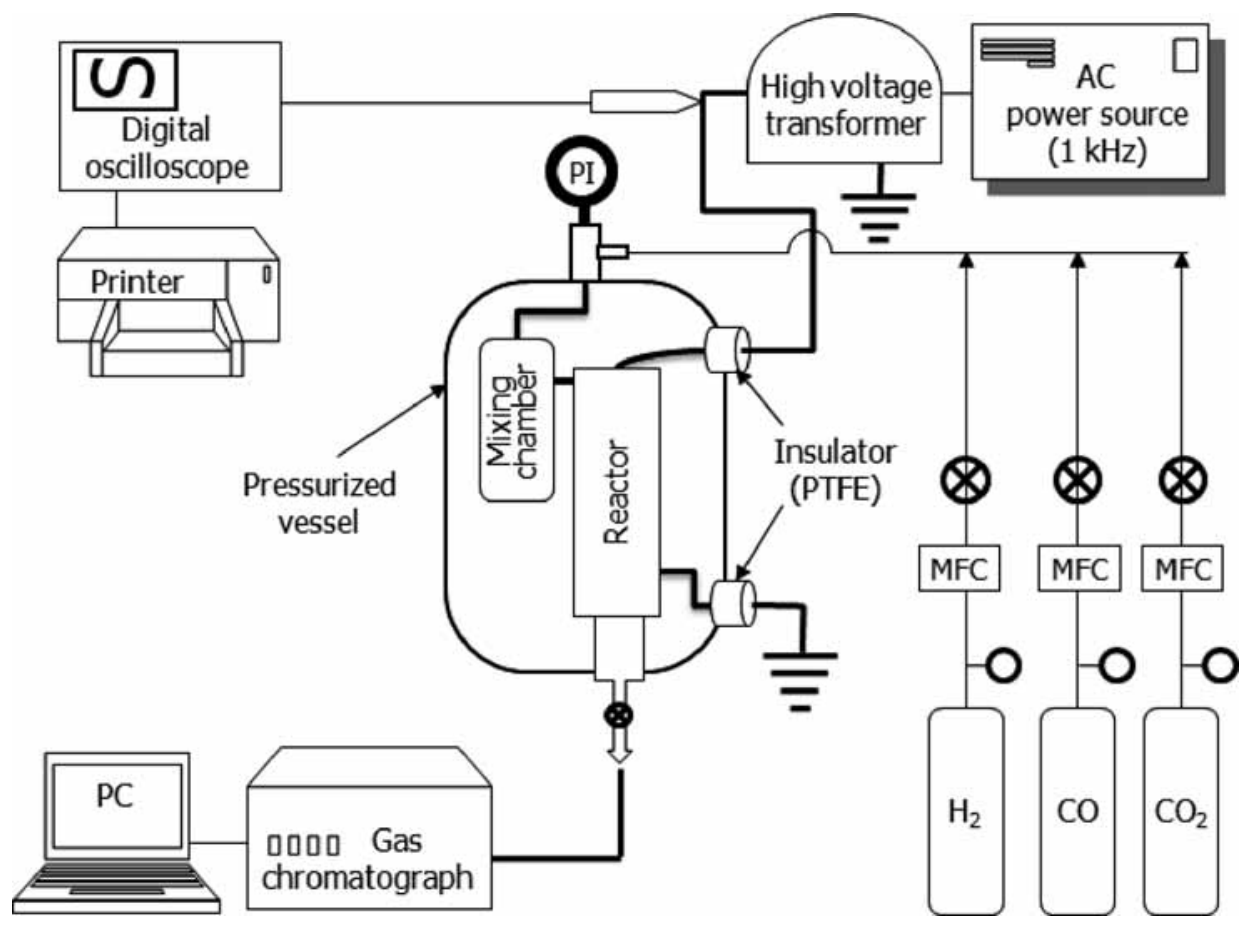

Figure 1: Schematic diagram of the experimental apparatus for methane synthesis. 
Table 2: Information on the catalysts used.

\begin{tabular}{lcccc}
\hline & Alumina & $\mathrm{TiO}_{2} /$ alumina & Ni/alumina & Ni-TiO 2 /alumina \\
\hline BET surface area $\left(\mathrm{m}^{2} \mathrm{~g}^{-1}\right)$ & 195.7 & 168.8 & 138.5 & 116.4 \\
$\mathrm{Ni}$ content $(\mathrm{wt} \%)$ & - & - & 10 & 10 \\
$\mathrm{TiO}_{2}$ content $(\mathrm{wt} \%)$ & - & 10 & - & 10 \\
\hline
\end{tabular}

with a heating tape and then directed to the plasma reactor with a heating tape in which the methanation of $\mathrm{CO} / \mathrm{CO}_{2}$ proceeded. The concentrations of $\mathrm{CO}, \mathrm{CO}_{2}, \mathrm{CH}_{4}$, and $\mathrm{H}_{2}$ in the effluent gas coming out of the reactor were analyzed by a gas chromatograph (Varian Micro GC CP-4900) equipped with an analytical column (10 m Pora Plot Q Column), using high purity helium as a carrier gas. The voltage applied to the reactor was measured with a 1,000:1 high voltage probe (P6015, Tektronix) and a digital oscilloscope (TDS 3032, Tektronix).

\section{RESULTS AND DISCUSSION}

Figures 2 and 3 present the effect of the reaction temperature on the conversions of $\mathrm{CO}$ and $\mathrm{CO}_{2}$ over $\mathrm{Ni}-\mathrm{TiO}_{2} / \mathrm{Al}_{2} \mathrm{O}_{3}$ catalyst at different voltages, where the equilibrium conversions calculated with eqns (6) and (7) are also given. The temperature was varied up to $320^{\circ} \mathrm{C}$ at each voltage level of $0.0,6.4,8.5$, and $10.3 \mathrm{kV}$. With the catalyst alone, that is, at a voltage of $0.0 \mathrm{kV}$, the conversion of $\mathrm{CO}$ slowly increased with increasing the temperature from $220^{\circ} \mathrm{C}$ to $300^{\circ} \mathrm{C}$, and then was saturated at about $96 \%$. As expected, there was a significant enhancement in the conversion rate when high voltage was applied to the reactor, resulting in higher conversion efficiencies at lower temperatures. Likewise, the conversion of $\mathrm{CO}_{2}$ showed a similar trend to that of $\mathrm{CO}$ (see Fig. 3). When the applied voltage is high enough to create plasma, active species, such as energetic electrons, ultraviolet (UV) photons, radicals, and excited molecules, are formed in the reactor [16]. As aforementioned, these active species can promote catalytic reactions through various channels, such as dissociation of adsorbed molecule and excitation of molecule. This may explain the enhancement of the conversion rate under the plasma conditions. Comparing at an identical voltage, the promotive effect of the plasma on the conversions of $\mathrm{CO}$ and $\mathrm{CO}_{2}$ was more notable at higher temperatures, that is, the difference in the conversion efficiency between with and without the plasma got wider as the temperature was increased. For instance, when the voltage was $10.3 \mathrm{kV}$, the difference in the conversion of $\mathrm{CO}_{2}$ between with and without the plasma was about $13 \%$ at $220^{\circ} \mathrm{C}$, while it was about $50 \%$ at $260^{\circ} \mathrm{C}$. The same trend was found with the $\mathrm{CO}$ methanation, though the difference between with and without the plasma was smaller. This result can partly be explained by the electron mean free path defined as the average distance between collisions. Suppose that temperature is increased at constant pressure, the mean free path increases by the expansion of gas. A longer mean free path enables an electron to be accelerated more to get more energy, eventually facilitating relevant reactions. In the meantime, the equilibrium conversions of $\mathrm{CO}$ and $\mathrm{CO}_{2}$ are calculated to be higher than those experimentally obtained. It is because the methanation reactions expressed as reactions (1) and (2) are highly exothermic and accordingly equilibrium is more favorable at low temperatures. Even if the equilibrium conversions were so, the kinetics is favored at high temperatures due to the presence of activation barrier.

The conversion efficiencies of $\mathrm{CO}$ and $\mathrm{CO}_{2}$ over three different catalysts at a temperature of $260^{\circ} \mathrm{C}$ are shown in Figs. 4 and 5 as a function of the applied voltage. As can be seen, there was 


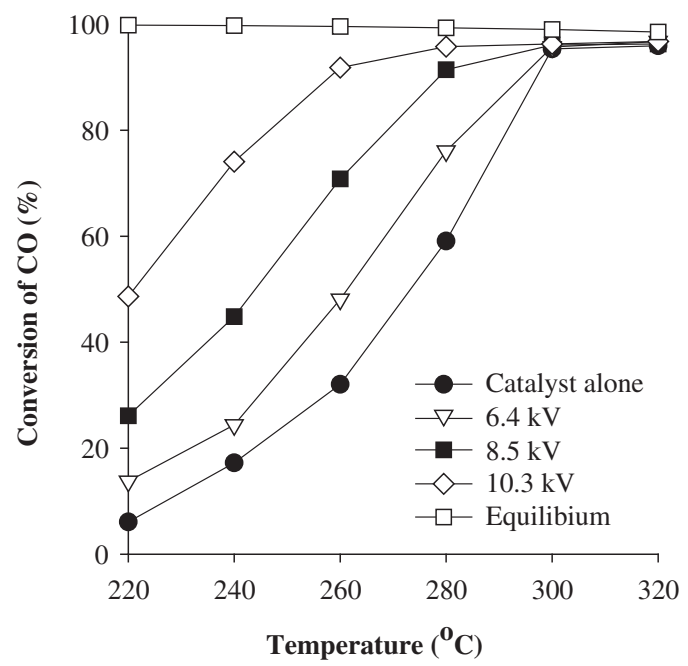

Figure 2: Effect of reaction temperature on the conversion $\mathrm{CO}$ at different voltages (catalyst: $\mathrm{Ni}-\mathrm{TiO}_{2} / \mathrm{Al}_{2} \mathrm{O}_{3}$ ).

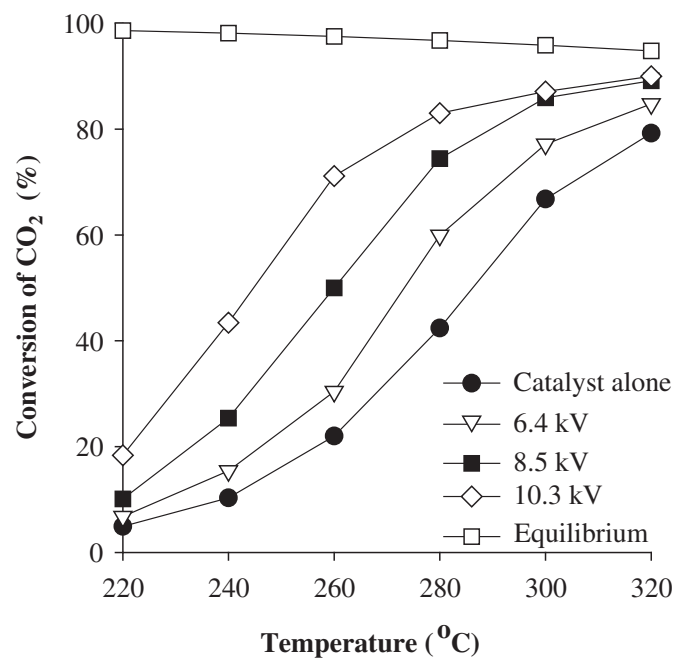

Figure 3: Effect of reaction temperature on the conversion $\mathrm{CO}_{2}$ at different voltages (catalyst: $\mathrm{Ni}-\mathrm{TiO}_{2} / \mathrm{Al}_{2} \mathrm{O}_{3}$ ).

negligible conversion of $\mathrm{CO}$ with either bare alumina or $\mathrm{TiO}_{2}$ /alumina catalyst, regardless of the voltage level, which implies that ultraviolet photons and gas-phase reactions formed by the plasma do not directly contribute to the production of methane. It should be noted that $\mathrm{TiO}_{2}$ photocatalyst in the anatase form whose band gap energy is about $3.2 \mathrm{eV}$ can be activated by ultraviolet photons with wavelengths $<390 \mathrm{~nm}$. The electron-impact excitation of CO emits ultraviolet light with various wavelengths $[22,23]$, but the photocatalytic effect was negligible with bare alumina and $\mathrm{TiO}_{2} /$ alumina. Different from the results obtained with bare alumina and $\mathrm{TiO}_{2}$ /alumina, the plasma largely 


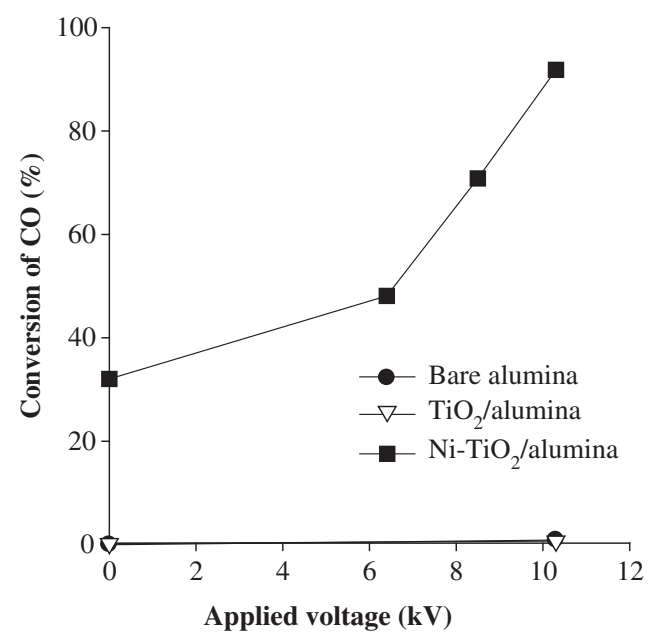

Figure 4: Conversion efficiencies of $\mathrm{CO}$ over different catalysts (temperature: $260^{\circ} \mathrm{C}$ ).

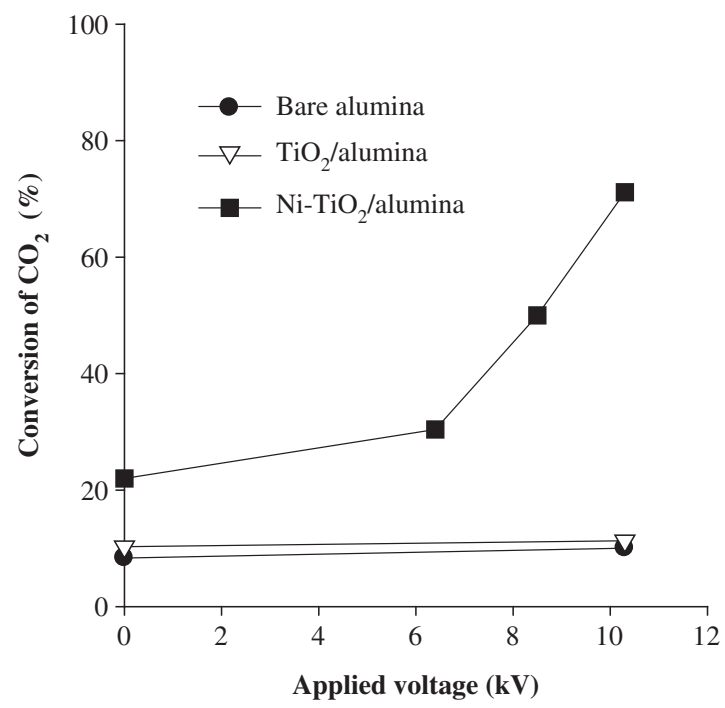

Figure 5: Conversion efficiencies of $\mathrm{CO}_{2}$ over different catalysts (temperature: $260^{\circ} \mathrm{C}$ ).

affected the conversion of $\mathrm{CO}$ over nickel-loaded alumina catalyst. As the voltage was increased, the conversion increased slowly at first and then rapidly. This enhancement suggests that the plasma can provide some additional activation of the catalyst. Like the case of $\mathrm{CO}$, the conversion of $\mathrm{CO}_{2}$ with bare alumina and $\mathrm{TiO}_{2}$ /alumina was not significant, and moreover, the $\mathrm{CO}_{2}$ converted was mostly reduced to $\mathrm{CO}$, not to methane.

In Fig. 6, the conversion efficiencies of $\mathrm{CO}$ and $\mathrm{CO}_{2}$ over $\mathrm{Ni}^{-\mathrm{TiO}_{2}}$ /alumina and $\mathrm{Ni}-\mathrm{TiO}_{2}$ /alumina that were obtained with the catalyst-alone and the plasma-catalyst are compared for a voltage of $8.5 \mathrm{kV}$ and a temperature of $260^{\circ} \mathrm{C}$. Either of the catalysts showed remarkable enhancements in the conversions of $\mathrm{CO}$ and $\mathrm{CO}_{2}$ as a result of the plasma generation in the catalytic reactor. Unexpectedly, 

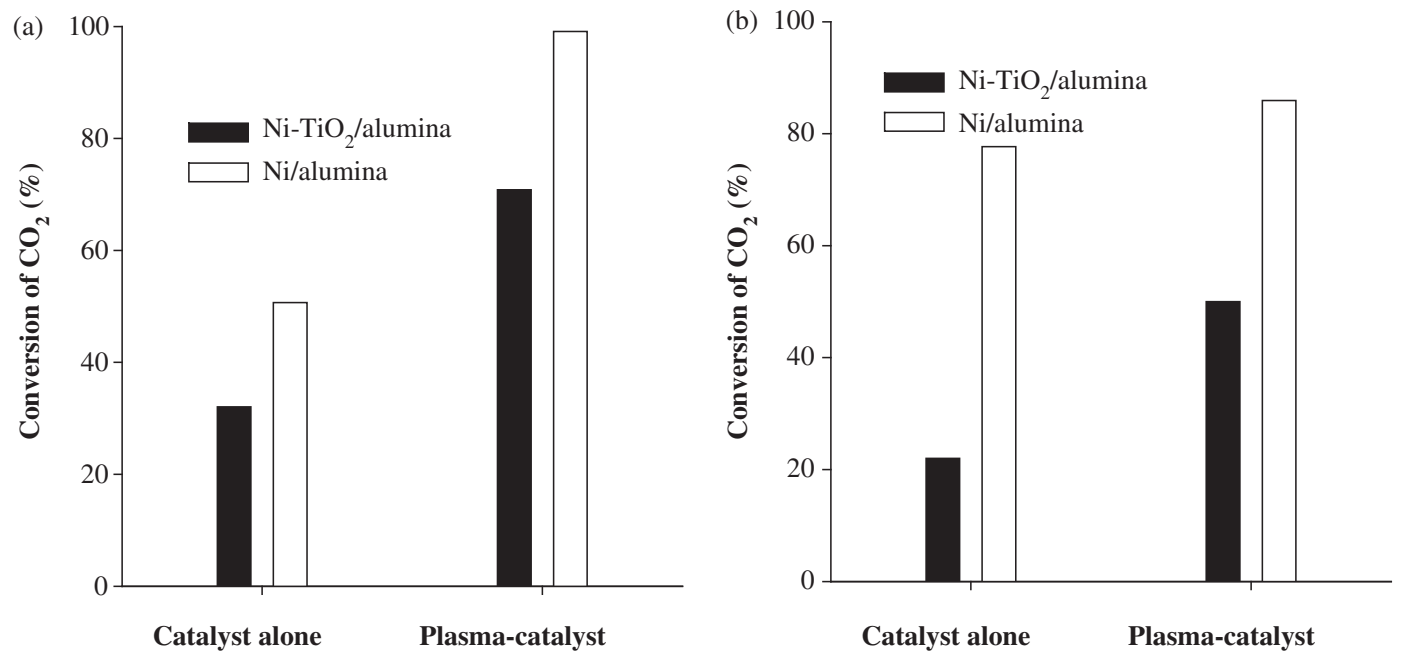

Figure 6: Comparison of conversion efficiencies between the catalyst-alone and the plasma-catalyst cases (a) for $\mathrm{CO}$ methanation and (b) for $\mathrm{CO}_{2}$ methanation (temperature: $260^{\circ} \mathrm{C}$; applied voltage: $8.6 \mathrm{kV})$.

the performance of $\mathrm{Ni}-\mathrm{TiO}_{2} / \mathrm{Al}_{2} \mathrm{O}_{3}$ catalyst was found to be inferior to that of $\mathrm{Ni} / \mathrm{Al}_{2} \mathrm{O}_{3}$ catalyst for both $\mathrm{CO}$ and $\mathrm{CO}_{2}$, which may be another evidence that the ultraviolet photons produced by the plasma did not contribute to the production of methanation. According to the literature [3], noble metals supported on titanium dioxide, such as $\mathrm{Pt} / \mathrm{TiO}_{2}, \mathrm{Rh} / \mathrm{TiO}_{2}$, and $\mathrm{Ir} / \mathrm{TiO}_{2}$, were reported to be effective for photo-induced dissociation of $\mathrm{CO}_{2}$, conflicting with the present study conducted with nickel as the active metal. It is believed that the photocatalytic activity of titanium dioxide is closely related to the nature of active metal and catalyst support. The lower performance of $\mathrm{Ni}-\mathrm{TiO}_{2} / \mathrm{Al}_{2} \mathrm{O}_{3}$ than $\mathrm{Ni} / \mathrm{Al}_{2} \mathrm{O}_{3}$ may also be attributed in part to its smaller BET specific surface area. As reported in Table 2, the BET specific surface areas of $\mathrm{Ni} /$ alumina and $\mathrm{Ni}-\mathrm{TiO}_{2}$ /alumina were measured to be 138.5 and $116.4 \mathrm{~m}^{3} / \mathrm{g}$, respectively. Even though not dealt with in detail, local heating of the catalyst surface due to the plasma generation may have somewhat contributed to the enhancement in the conversions of $\mathrm{CO}$ and $\mathrm{CO}_{2}$, because the catalysts used in this work are dielectric. To minimize such a dielectric heating effect and make a comparison between the catalyst-alone and the plasma-catalyst cases at an identical temperature condition, the reactor temperature was minutely controlled, and the concentrations of relevant compounds $\left(\mathrm{CO}, \mathrm{CO}_{2}, \mathrm{CH}_{4}\right.$, etc.) were measured after a lapse of time long enough to ensure that the temperature reached the same temperature as in the case of the catalystalone. To sum up, the local dielectric heating effect is believed to be minor.

\section{CONCLUSIONS}

This work investigated the use of nonthermal plasma created in a catalyst-packed bed reactor to convert $\mathrm{CO}$ and $\mathrm{CO}_{2}$ into methane in the presence of hydrogen. So as to understand the role of nonthermal plasma in the catalytic methanation, several catalysts, including bare alumina, $\mathrm{TiO}_{2}$ /alumina, $\mathrm{Ni}$ /alumina and $\mathrm{Ni}-\mathrm{TiO}_{2} /$ alumina, were examined. It was found that the plasma was beneficial to the catalytic conversion of $\mathrm{CO}$ and $\mathrm{CO}_{2}$ in that it shifted the optimal reaction temperature lower. The experimental data obtained by varying the catalyst composition have shown that the enhancement in the rate of the conversion by the plasma results from speeding up the rate-determining step, and the contributions of gas-phase reactions and photocatalysis caused by the plasma are insignificant. 


\section{ACKNOWLEDGMENT}

This research was supported by Basic Science Research Program through the National Research Foundation of Korea (NRF) funded by the Ministry of Education, Science and Technology (Grant number 2010-0021672).

\section{REFERENCES}

[1] Chandel, M. \& Williams, E., Synthetic Natural Gas (SNG): Technology, Environmental Implications, and Economics. Climate Change Policy Partnership, Duke University: Durham, NC, USA, 2009.

[2] Yaccato, K., Carhart, R., Hagemeyer, A. Lesik, A., Strasser, P., Volpe Jr., A.F., Turner, H., Weinberg, H., Grasselli, R.K. \& Brooks, C., Competitive $\mathrm{CO}$ and $\mathrm{CO}_{2}$ methanation over supported noble metal catalysts in high throughput scanning mass spectrometer. Applied Catalysis A: General, 296, pp. 30-48, 2005. doi: http://dx.doi.org/10.1016/j.apcata.2005.07.052

[3] Rasko, J., FTIR study of the photoinduced dissociation of $\mathrm{CO}_{2}$ on titania-supported noble metals. Catalysis Letters, 56, pp. 11-15, 1998. doi: http://dx.doi.org/10.1023/A:1019072021006

[4] Men, Y., Kolb, G., Zapf, R., Hessel, V. \& Lowe, H., Selective methanation of carbon oxides in a microchannel reactor-Primary screening and impact of gas additives. Catalysis Today, 125, pp. 81-87, 2007. doi: http://dx.doi.org/10.1016/j.cattod.2007.02.017

[5] Sehested, J., Dahl, S., Jacobsen, J. \& Rostrup-Nielsen, J.R., Methanation of CO over nickel: mechanism and kinetics at high $\mathrm{H}_{2} / \mathrm{CO}$ ratios. Journal of Physical Chemistry B, 109, pp. 2432-2438, 2005. doi: http://dx.doi.org/10.1021/jp040239s

[6] Pangiotopoulou, P., Knonarides, D.I. \& Verykios, X.E., Selective methanation of CO over supported noble metal catalysts: effects of the nature of the metallic phase on catalytic performance. Applied Catalysis A, 344, pp. 45-54, 2006. doi: http://dx.doi.org/10.1016/j.apcata. $\underline{2008.03 .039}$

[7] Yadav, R. \& Rinker, R.G., Steady-state methanation kinetics over a $\mathrm{Ni} / \mathrm{Al}_{2} \mathrm{O}_{3}$ catalyst. Canadian Journal of Chemical Engineering, 71, pp. 202-208, 1993. doi: http://dx.doi.org/10.1002/ cjce. 5450710206

[8] Alstrup, I., On the kinetics of CO methanation on nickel surfaces. Journal of Catalysis, 151, pp. 216-225, 1995. doi: http://dx.doi.org/10.1006/jcat.1995.1023

[9] Fujita, S.I. \& Takezawa, N., Difference in the selectivity of $\mathrm{CO}$ and $\mathrm{CO}_{2}$ methanation reactions. Chemical Engineering Journal, 68, pp. 63-68, 1997. doi: http://dx.doi.org/10.1016/ $\underline{\text { S1385-8947(97)00074-0 }}$

[10] Havran, V., Dudukovic, M.P. \& Lo, C.S., Conversion of methane and carbon dioxide to higher value products. Industrial and Engineering Chemistry Research, 50, pp. 7089-7100, 2011. doi: http://dx.doi.org/10.1021/ie2000192

[11] Jeon, S.G., Kim, K.H., Shin, D.H., Nho, N.S. \& Lee, K.H., Effective combination of nonthermal plasma and catalyst for removal of volatile organic compounds and $\mathrm{NO}_{\mathrm{x}}$. Korean Journal of Chemical Engineering, 24(3), pp. 522-526, 2007. doi: http://dx.doi.org/10.1007/ s11814-007-0092-9

[12] Nozaki, T., Tsukijihara, H., Fukui, W. \& Okazaki, K., Kinetic analysis of the catalyst and nonthermal plasma hybrid reaction for methane steam reforming. Energy \& Fuels, 21(5), pp. 2525-2530, 2007. doi: http://dx.doi.org/10.1021/ef070117+

[13] Sobacchi, M.G., Saveliev, A.V., Fridman, A.A., Kennedy, L.A., Ahmed, S. \& Krause, T., Experimental assessment of a combined plasma/catalytic system for hydrogen production via partial oxidation of hydrocarbon fuels. International Journal of Hydrogen Energy, 27, pp. 635-642, 2002. doi: http://dx.doi.org/10.1016/S0360-3199(01)00179-3 
[14] Kim, D.H., Mok, Y.S. \& Lee, S.B., Effect of temperature on the decomposition of trifluoromethane in a dielectric barrier discharge reactor. Thin Solid Films, 519(20), pp. 6960-6963, 2011. doi: http://dx.doi.org/10.1016/j.tsf.2010.11.060

[15] Mok, Y.S., Kang, H.C., Lee, H.J., Koh, D.J. \& Shin, D.N., Effect of nonthermal plasma on the methanation of carbon monoxide over nickel catalyst. Plasma Chemistry and Plasma Processing, 30, pp. 437-447, 2010. doi: http://dx.doi.org/10.1007/s11090-010-9231-x

[16] Jwa, E., Mok, Y.S. \& Lee, S.B., Nonthermal plasma-assisted catalytic methanation of CO and $\mathrm{CO}_{2}$ over nickel-loaded alumina. WIT Transactions on Ecology and the Environment, WIT Press: UK, 143, pp. 361-368, 2011.

[17] Smith, J.M. \& Van Ness, H.C., Introduction to Chemical Engineering Thermodynamics, 3rd edn, McGraw-Hill Book Company: New York, 1985.

[18] Thompson, Jr., L.T., Schwank, J. \& Curtis, M.D., CO hydrogenation over alumina-supported sulfide cluster catalysts. AIChE Journal, 35(1), pp. 109-119, 1989. doi: http://dx.doi.org/ $\underline{10.1002 / a i c .690350112}$

[19] Akin, A.N., Ataman, M., Aksoylu, A.E. \& Onsan, Z.I., $\mathrm{CO}_{2}$ fixation by hydrogenation over coprecipitated $\mathrm{Co} / \mathrm{Al}_{2} \mathrm{O}_{3}$. Reaction Kinetics and Catalysis Letters, 76(2), pp. 265-270, 2002. doi: http://dx.doi.org/10.1023/A:1016579726726

[20] Bengaard, H.S., Nørskov, J.K., Sehested, J., Clausen, B.S., Nielsen, L.P., Molenbrock, A.M. \& Rostrup-Nielsen, J.R., Steam reforming and formation of graphite on Ni catalysts. Journal of Catalysis, 209, 365-384, 2002. doi: http://dx.doi.org/10.1006/jcat.2002.3579

[21] Choe, S.J., Kang, H.J., Kim, S.J., Park, S.B., Park, D.H. \& Huh, D.S., Adsorbed carbon formation and carbon hydrogenation for $\mathrm{CO}_{2}$ methanation on the $\mathrm{Ni}(111)$ surface: ASED-MO study. Bulletin of the Korean Chemical Society, 26(11), pp. 1682-1688, 2005. doi: http://dx.doi. org/10.5012/bkcs.2005.26.11.1682

[22] Olszewski, R., Wolinski, P. \& Zubek, M., Excitation of carbon monoxide by electron impact in the 8-17 eV energy range. Chemical Physics Letters, 297, pp. 537-542, 1998. doi: http:// dx.doi.org/10.1016/S0009-2614(98)01153-1

[23] Mogul, R. Bolshakov, A.A., Chan, S.L., Stevens, R.M., Khare, B.N., Meyyappan, M. \& Trent, J.D., Impact of low-temperature plasmas on deinococcus radiodurans and biomolecules. Biotechnology Progress, 19, pp. 776-783, 2003. doi: http://dx.doi.org/10.1021/bp025665e 